\title{
Perineural Invasion Is a Prognostic Factor and Treatment Indicator in Patients with Rectal Cancer Undergoing Curative Surgery: 2000-2011 Data from a Single-center Study
}

\author{
TETSUSHI KINUGASA ${ }^{1}$, TOMOAKI MIZOBE ${ }^{1}$, SACHIKO SHIRAIWA ${ }^{1}$, \\ YOSHITO AKAGI ${ }^{1}$ and KAZUO SHIROUZU ${ }^{1,2}$ \\ ${ }^{1}$ Department of Surgery, Kurume University School of Medicine, Kurume, Japan; \\ ${ }^{2} J a p a n$ Community Health Care Organization Kurume General Hospital, Kurume, Japan
}

\begin{abstract}
Background/Aim: The aim of the present study was to investigate whether perineural invasion (PNI) was a prognostic index for patients who underwent curative surgery for Dukes' grade B and C rectal cancer. Patients and Methods: A total of 645 patients with rectal cancer between January 2000 and December 2011; 363 with Dukes' B or C stages who did not undergo chemoradiotherapy were reviewed. Results: Of 363 patients, 83 (22.9\%) were PNIpositive. The 5-year overall survival and disease-specific survival rates were significantly worse for patients with PNIpositive Dukes' B or C disease compared to those with PNInegative disease. There was no significant difference in the recurrence pattern (hematogenous or lymphatic spread), but patients with PNI-positive disease had a significantly higher rate of recurrence compared to those with PNI-negative disease $(p<0.001)$. Conclusion: PNI was a significant prognostic factor in rectal cancer, and the PNI status in primary rectal cancer pathology specimens should be considered for therapy stratification.
\end{abstract}

Colorectal cancer (CRC) is the third most common cancer and is the leading cause of cancer deaths in Japan, with more than 100,000 new cases and 36,000 deaths annually (1). The most important prognostic factors for predicting disease-free and overall survival (OS) rates are local recurrence and distant metastasis (2). Tumor penetration depth and lymph node metastasis are also standard prognostic determinants for CRC; until recently, the survival rates for patients with colon cancer were generally better than for those with rectal cancer

Correspondence to: Dr. Tetsushi Kinugasa, Department of Surgery, Kurume University School of Medicine, 67 Asahi-machi, Kurume, Fukuoka 830-0011, Japan. Tel: +81 942353311, Fax: +81 942340709, e-mail: kinugasa_tetsushi@med.kurume-u.ac.jp

Key Words: Perineural invasion, rectal cancer, prognostic factor.
(3-6). The above indicators are also important for Dukes staging (5) and tumor node metastasis (TNM) classification (7). However, some investigators emphasize the need to develop alternative measures related to tumor growth characteristics $(8,9)$.

A complex network of autonomic nerves envelops the rectum. Following a report by Seefeld and Bargen (10), various studies have suggested that perineural invasion (PNI) may be an effective indicator of survival (11-16) and local recurrence $(11,13,17,18)$. PNI is one of the most widely studied pathological factors in pw malignant tumors. As perineural nerve fibers are sheathed, PNI was defined by Batsakis as tumor cell invasion in, around, and through the nerve in neurotropic carcinomas (19), although this definition has been challenged (20). The prognostic significance of PNI is widely acknowledged in malignancies of the head and neck and of the prostate (21-23), but remains unclear in CRC (24-27).

To date, there has been little work on developing an objective PNI grading system with which patients can be recommended for postoperative adjuvant chemotherapy. The aim of this study was to investigate whether PNI is a useful prognostic marker for patients who underwent curative surgery for rectal cancer.

\section{Patients and Methods}

Patient and tissue samples. A total of 645 patients with rectal cancer underwent curative surgery at Kurume University Hospital in Fukuoka between January 2000 and December 2011, 363 patients with Dukes' stages B or C, who received no preoperative chemoradiation therapy were reviewed. Informed consent was obtained from each of the patients before performing surgical resection, and the Institutional Review Committee for Research on Human Subjects at Kurume University Hospital approved the study (no. 2323). All 363 patients underwent surgery, their surgical approach was uniformly mesenteric-based total mesorectal excision or tumor specific mesorectal excision, and their mean duration of 
postoperative follow-up was 92.0 months. The resected whole tumor mass was sliced into longitudinal serial sections, each $5 \mathrm{~mm}$ thick, with the adjoining intestinal wall containing extramural fatty tissue (28). PNI was judged to be present when cancer cells were found to exist inside the perineurium (13). Histopathological classification was performed according to the General Rules for Colorectal Cancer Study (29), and clinicopathological factors were assessed according to Dukes' classification (5).

Follow-up and data recording. The follow-up procedures were defined according to the Japanese Consensus Conference on Colon Cancer Management (29). For all surviving patients, follow-up data were obtained during routine clinical care.

A tree model was used designating the response variable as PNI positive or PNI negative, and the explanatory variables as the criteria derived by univariate analysis. Such a model can deal automatically with the problem of interaction between the many explanatory variants, permits easy interpretation of numerical and factorial variants existing side by side, and helps reveal hidden pattern structures in the data (30).

Endpoints. The 5-year OS and the 5-year disease-specific survival (DSS) rates were analyzed for the overall study population.

Statistical analysis. Statistical analysis was performed using JMP version 10.0 (SAS Institute Inc., Cary, NC USA). Survival distributions were estimated using the adjusted Kaplan-Meier method and compared using a log-rank test. OS was based on the time between diagnosis and the date of death or most recent followup. DSS was based on the time between diagnosis and the date of recurrence. Uni- and multivariate analyses were performed using Cox proportional hazard models. Values of $p<0.05$ were considered to indicate statistical significance.

\section{Results}

Clinicopathological characteristics. Patient clinical and pathological characteristics are summarized in Table I. A total of 363 patients with Dukes B or C rectal cancer underwent curative surgery. Their mean age at the time of resection was 64.5 years (range $=17-89$ years). There were $149(41.0 \%)$ tumors located in the lower rectum, and $182(50.1 \%)$ cases were well differentiated. There were $156(43 \%)$ cases presenting with perirectal lymph node metastasis, and 330 (90.9\%) tumors were determined to be at T3 or T4 depth of invasion.

Incidence of PNI in patients with rectal cancer and correlation with other factors. A total of 83 (22.9\%) cases were PNI-positive. Univariate analysis for associations between PNI and clinicopathological findings was performed. Considering the location, $27 \%$ of cases of cancer of the upper and middle rectum were PNI-positive, compared to $16.8 \%$ of those with cancer of the lower rectum $(p=0.0225)$. Histologically, $13.7 \%$ of well-differentiated tumors were PNIpositive, compared to $30.9 \%$ of non-well-differentiated lesions $(p<0.0001)$. No T1 or T2 tumors were found to be PNI- positive, whereas $7.9 \%$ of T3 and $34.3 \%$ of T4 were
Table I. Relationship between perineural invasion (PNI) and clinicopathological characteristics using the Chi-square test.

\begin{tabular}{|c|c|c|c|c|}
\hline & $\begin{array}{l}\text { No. of } \\
\text { patients } \\
(n=363)\end{array}$ & $\begin{array}{c}\text { PNI- } \\
\text { negative } \\
(n=280)\end{array}$ & $\begin{array}{c}\text { PNI- } \\
\text { positive } \\
(\mathrm{n}=83)\end{array}$ & $p$-Value \\
\hline \multicolumn{5}{|l|}{ Gender } \\
\hline Male & 249 & 187 & 62 & \multirow[t]{2}{*}{0.1861} \\
\hline Female & 114 & 93 & 21 & \\
\hline \multicolumn{5}{|l|}{ Location } \\
\hline $\mathrm{RS}+\mathrm{Ra}$ & 214 & 156 & 58 & \multirow[t]{2}{*}{$<0.0225$} \\
\hline $\mathrm{Rb}$ & 149 & 124 & 25 & \\
\hline \multicolumn{5}{|c|}{ Histological grade } \\
\hline Well & 182 & 157 & 25 & \multirow{5}{*}{$\begin{array}{c}\text { Well vs. } \\
\text { non-well, } \\
<0.0001\end{array}$} \\
\hline Mod & 154 & 105 & 49 & \\
\hline Poor & 11 & 5 & 6 & \\
\hline Muc & 13 & 12 & 1 & \\
\hline Other & 3 & 3 & 0 & \\
\hline \multicolumn{5}{|c|}{ Depth of invasion } \\
\hline $\mathrm{T} 1$ & 7 & 7 & 0 & \multirow{4}{*}{$\begin{array}{c}\mathrm{T} 1+\mathrm{T} 2 v s \\
\mathrm{~T} 3+\mathrm{T} 4 \\
<0.0001\end{array}$} \\
\hline $\mathrm{T} 2$ & 26 & 26 & 0 & \\
\hline $\mathrm{T} 3$ & 114 & 105 & 9 & \\
\hline $\mathrm{T} 4$ & 216 & 142 & 74 & \\
\hline \multicolumn{5}{|c|}{$\begin{array}{l}\text { Perirectal lymph } \\
\text { node metastasis }\end{array}$} \\
\hline No & 101 & 79 & 22 & \multirow[t]{3}{*}{$<0.0277$} \\
\hline Yes & 156 & 102 & 54 & \\
\hline Unknown & 106 & - & - & \\
\hline \multicolumn{5}{|c|}{$\begin{array}{l}\text { Lateral lymph } \\
\text { node metastasis }\end{array}$} \\
\hline No & 241 & 173 & 68 & \multirow[t]{3}{*}{0.087} \\
\hline Yes & 16 & 8 & 8 & \\
\hline Unknown & 106 & - & - & \\
\hline \multicolumn{5}{|c|}{ Lymphatic invasion } \\
\hline No & 150 & 137 & 13 & \multirow[t]{3}{*}{$<0.0001$} \\
\hline Yes & 213 & 143 & 70 & \\
\hline Unknown & 0 & 0 & 0 & \\
\hline \multicolumn{5}{|c|}{ Venous invasion } \\
\hline No & 43 & 39 & 4 & \multirow[t]{3}{*}{$<0.0014$} \\
\hline Yes & 199 & 133 & 66 & \\
\hline Unknown & 121 & - & - & \\
\hline \multicolumn{5}{|l|}{ Budding } \\
\hline No & 106 & 99 & 7 & \multirow[t]{3}{*}{$<0.0001$} \\
\hline Yes & 243 & 169 & 74 & \\
\hline Unknown & 14 & - & - & \\
\hline
\end{tabular}

PNI: Perineural invasion, RS: upper rectum, Ra: middle rectum, Rb: lower rectum, Well: well-differentiated adenocarcinoma, Mod: moderately differentiated adenocarcinoma, Poor: poorly differentiated adenocarcinoma, Muc: mucinous adenocarcinoma.

indicating that PNI significantly positively correlated with depth of invasion $(p<0.0001)$. Furthermore, $34.8 \%$ patients with positive and $21.8 \%$ of those with negative perirectal lymph node metastasis were PNI-positive $(p<0.0277)$. Regarding lymphatic invasion, venous invasion, and budding, 
a

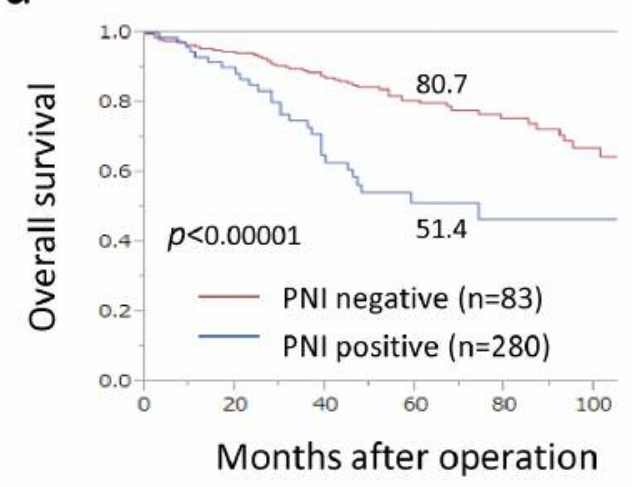

b Dukes' B patients ( $n=161)$

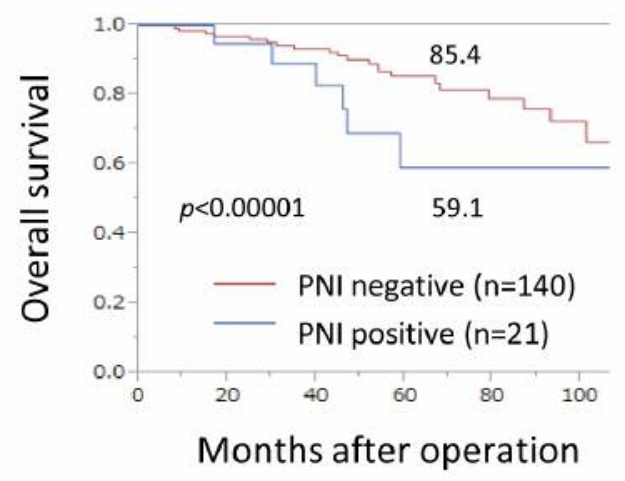

C

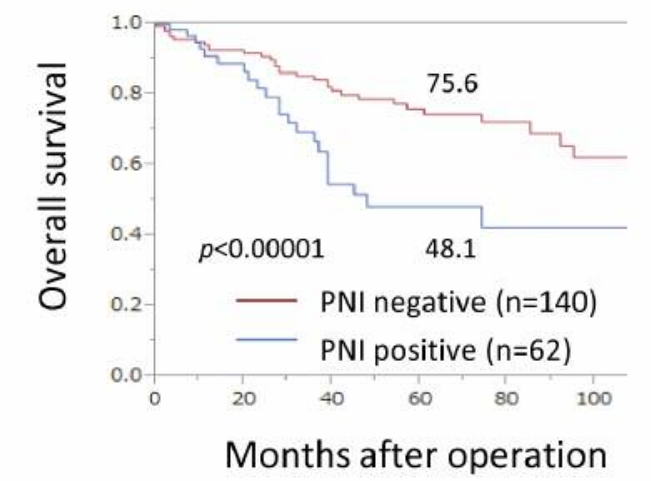

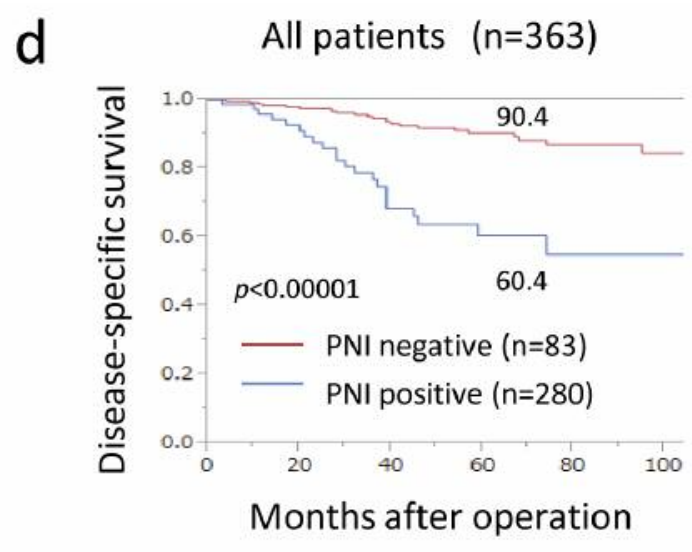

e

Dukes' $B$ patients $(n=161)$

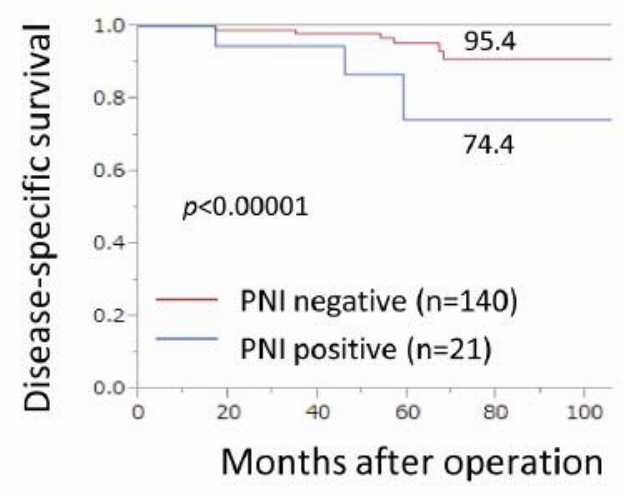

f

Dukes' $C$ patients ( $n=202$ )

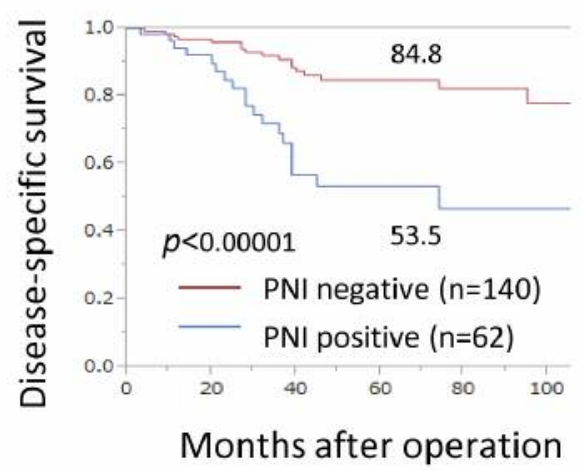

Figure 1. Kaplan-Meier survival curves of overall $(a-c)$ and disease-specific $(d-f)$ survival according to perineural invasion (PNI) for all patients with Dukes' B or C $(a, d)$, patients with Dukes' $B(b, e)$, and Dukes' $C(c, f)$ disease.

there was a significant difference in the incidence rate of PNIpositive $v s$. PNI-negative groups. However, there was no such difference in lateral lymph node metastasis.

Role of PNI as a prognostic factor for outcome in patients with rectal cancer. Using univariate and multivariate logistic analyses, PNI was investigated as a prognostic factor, as were other clinical and pathological findings. Patients with PNI-negative tumors had a 1.5-fold increase in 5-year OS compared to patients with PNI-positive ones $(80.7 \%$ vs. $51.4 \%$, respectively; $p<0.00001$ ) (Figure 1a). The 5-year OS was longer for patients with PNI-negative Dukes' B than for 
those with PNI-positive tumors $(85.4 \%$ vs. $59.1 \%$, respectively; $p<0.00001$ ) (Figure $1 \mathrm{~b}$ ); the same trend was observed in patients with Dukes' C disease (75.6\% vs. $48.1 \%$, respectively; $p<0.00001$ ) (Figure 1c). Moreover, the 5-year DSS was longer for patients with PNI-negative tumors than for those with PNI-positive tumors (90.4\% vs. $60.4 \%$, respectively; $p<0.00001$ ) (Figure 1d). In patients with Dukes' B disease, the 5-year DSS was longer for patients with PNI-negative tumors than for those with PNIpositive tumors (95.4\% vs. $74.4 \%$, respectively; $p<0.00001$ ) (Figure 1e), as was the case for those with Dukes' $\mathrm{C}$ disease (84.8\% vs. $53.5 \%$, respectively; $p<0.00001$ ) (Figure 1f).

Association between PNI positivity and DSS. Recurrence was found in $79(21.7 \%)$ out of the 363 patients in this study. Table II shows the correlation between PNI and organs of recurrence. The PNI status had no significant effect on individual organ recurrence patterns, irrespective of hematogenous or lymphatic spread and systemic or local recurrence. Among those with 83 PNI-positive tumors, recurrence occurred in 47 (56.6\%) cases, whereas in the 280 PNI-negative cases, recurrence occurred in $32(11.4 \% ; p<0.001)$.

We analyzed postoperative DSS using a Cox proportional hazard model (Table III). In the univariate analysis, tumor depth $(p=0.084)$, histological grade $(p<0.001)$, perirectal lymph node metastasis $(p=0.0017)$, lateral lymph node metastasis $(p=0.0002)$, lymphatic invasion $(p=0.0036)$, venous invasion $(p=0.0072)$, budding $(p=0.0012)$ and PNI $(p<0.001)$ were significant prognostic factors for poorer DSS. In the multivariate analysis, lateral lymph node metastasis $(p=0.039)$ and PNI $(p=0.0005)$ were independent prognostic factors for poorer DSS.

In order to investigate PNI for its potential clinical use in rectal cancer therapy and prognosis, a probing analysis of the data using the tree model was performed for recurrence. The 363 patients were divided into the following three groups: group I, patients with PNI-negative well-differentiated adenocarcinoma $(n=157,44.3 \%)$; group II, patients with PNI-negative non-well-differentiated adenocarcinoma $(\mathrm{n}=123,33.9 \%)$; and group III, patients with PNI-positive disease $(n=83,22.9 \%)$ (Figure 2$)$. The 5-year DSS was $92.2 \%, 88.0 \%$, and $60.5 \%$, for groups I, II, and III, respectively (I vs. III; $p<0.000001$; Figure 3a). The 5-year DSS was $95.4 \%, 96.0 \%$, and $74.4 \%$, respectively, in those with Dukes' B (I vs. III; $p<0.000001$ ), and 87.2\%, 83.2\%, and $53.5 \%$, respectively, those with in Dukes' C (I vs. III; $p<0.000001$; Figure $3 b$ and $3 c)$.

\section{Discussion}

Although a single-center study, our findings suggested that PNI may be a useful prognostic marker in rectal cancer, and that patients with PNI-positive disease should be consider a
Table II. Association between perineural invasion (PNI) and recurrence/metastasis after curative surgery for rectal cancer using the Chi-square test.

\begin{tabular}{lcccc}
\hline $\begin{array}{l}\text { Site of recurrence/ } \\
\text { metastasis }\end{array}$ & $\begin{array}{c}\text { No. of } \\
\text { patients }\end{array}$ & $\begin{array}{c}\text { PNI- } \\
\text { negative }\end{array}$ & $\begin{array}{c}\text { PNI- } \\
\text { positive }\end{array}$ & $p$-Value \\
\hline Liver & 12 & 4 & 8 & 0.75 \\
Lungs & 14 & 5 & 9 & 0.77 \\
Liver and lungs & 8 & 3 & 5 & 1 \\
Liver/lungs and local & 8 & 5 & 3 & 0.258 \\
Bone & 1 & 0 & 1 & 1 \\
Local & 19 & 9 & 10 & 0.591 \\
Local and peritoneal & 2 & 1 & 1 & 1 \\
Peritoneal dissemination & 5 & 2 & 3 & 1 \\
Lymph nodes & 9 & 3 & 6 & 0.732 \\
Brain & 1 & 0 & 1 & 1 \\
Total & 79 & 32 & 47 & \\
\hline
\end{tabular}

high-risk group after curative surgery for patients with Dukes' B or C. There was no PNI-specific recurrence pattern but the overall recurrence rate was significantly higher in those with PNI-positive than in PNI-negative disease. PNIpositive Dukes' B rectal cancer should be classified in a higher risk group and considered for treatment using currently available effective adjuvant therapies.

PNI refers to cancer involving the space surrounding a nerve, and was first described in primary head and neck tumors in 1862 by Neumann (31). PNI has been studied in many malignancies, including prostate, head and neck, and gastrointestinal tract cancer, yet, there is still no agreement on the definition of PNI positivity $(22,32-34)$. While PNI is increasingly appreciated, it is still an understudied feature of rectal tumor biology although it continues to be investigated in head and neck tumors and in prostate cancer (35-38). In $\mathrm{CRC}$, the incidence of PNI positivity ranges from $<10 \%$ to $33 \%$ (27, 39-41). Liebig et al. described PNI in stages I-IV CRC (27), with a detection rate of $0.5-22 \%$, further suggesting that PNI positivity may easily be missed or ignored by clinical pathologists. Therefore, guidelines that incorporate PNI evaluation would be beneficial. There is a lack of standardized criteria for a PNI-positive finding, although it is seen as a pathological feature not only of CRC but also of other malignant tumors $(42,43)$. PNI is observed both intramurally and extramurally, and there is no sitespecific assessment rule for PNI in the large bowel. In our series, approximately $20 \%$ of tumors were discovered to be PNI-positive (83 of 363 cases) on pathological analysis at the time of resection.

The mechanisms of PNI remain poorly understood. The clear association between PNI and metastasis in several cancer types strongly suggests a role for PNI in tumor dissemination. The most common sites of rectal cancer metastasis are the 
Table III. Uni-and multivariate analyses using the Cox proportional hazard model for disease specific survival.

\begin{tabular}{|c|c|c|c|c|c|c|c|}
\hline \multirow[t]{2}{*}{ Variable } & \multirow[t]{2}{*}{$\mathrm{n}$} & \multicolumn{3}{|c|}{ Univariate analysis } & \multicolumn{3}{|c|}{ Multivariate analysis } \\
\hline & & HR & $(95 \% \mathrm{CI})$ & $p$-Value & HR & $(95 \% \mathrm{CI})$ & $p$-Value \\
\hline \multicolumn{8}{|l|}{ Gender } \\
\hline Male & 249 & 1.05 & $(0.88-1.24)$ & 0.542 & & & \\
\hline Female & 114 & 1 & & & & & \\
\hline \multicolumn{8}{|l|}{ Location } \\
\hline $\mathrm{RS}+\mathrm{Ra}$ & 214 & 1 & & 0.787 & & & \\
\hline $\mathrm{Rb}$ & 149 & 1.02 & $(0.87-1.19)$ & & & & \\
\hline \multicolumn{8}{|c|}{ Histologic grade } \\
\hline Well & 182 & 1 & & $<0.0001 *$ & 1 & & 0.062 \\
\hline Non-well & 181 & 1.39 & $(1.18-1.64)$ & & 1.29 & $(0.98-1.70)$ & \\
\hline \multicolumn{8}{|c|}{ Depth of invasion } \\
\hline $\mathrm{T} 1+\mathrm{T} 2$ & 33 & 1 & & $0.0084 *$ & 1 & & 0.58 \\
\hline $\mathrm{T} 3+\mathrm{T} 4$ & 230 & 1.24 & $(1.05-1.47)$ & & 1.11 & $(0.76-1.57)$ & \\
\hline \multicolumn{8}{|c|}{ Perirectal lymph node metastasis } \\
\hline Negative & 101 & 1 & & $0.0017 *$ & 1 & & 1.04 \\
\hline Positive & 156 & 1.39 & $(1.13-1.71)$ & & 1.04 & $(0.98-1.70)$ & \\
\hline \multicolumn{8}{|c|}{ Lateral lymph node metastasis } \\
\hline Negative & 241 & 1 & & $0.0002 *$ & 1 & & $0.039 *$ \\
\hline Positive & 16 & 2.93 & $(1.74-4.62)$ & & 1.76 & $(1.02-2.85)$ & \\
\hline \multicolumn{8}{|c|}{ Lymphatic invasion } \\
\hline Negative & 150 & 1 & & $0.0036^{*}$ & 1 & & 0.89 \\
\hline Positive & 213 & 1.26 & $(1.08-1.49)$ & & 1.04 & $(0.48-1.92)$ & \\
\hline \multicolumn{8}{|c|}{ Venous invasion } \\
\hline Negative & 43 & 1 & & $0.0072 *$ & 1 & & 0.43 \\
\hline Positive & 199 & 1.31 & $(1.07-1.60)$ & & 1.21 & $(0.75-2.06)$ & \\
\hline \multicolumn{8}{|c|}{ Perineural invasion } \\
\hline Negative & 280 & 1 & & $<0.0001 *$ & 1 & & $0.0005^{*}$ \\
\hline Positive & 83 & 2.01 & $(1.62-2.45)$ & & 1.68 & $(1.25-2.24)$ & \\
\hline \multicolumn{8}{|l|}{ Budding } \\
\hline Negative & 106 & 1 & & $0.0012 *$ & NS & & \\
\hline Positive & 243 & 1.32 & $(1.11-1.56)$ & & & & \\
\hline
\end{tabular}

liver, lungs, and retroperitoneum, all richly innervated by autonomic nerve fibers. The sympathetic fibers innervating the liver share a preganglionic origin with the sympathetic nerves that innervate the colon and rectum (44). Although this hypothetical route for rectal cancer metastasis has not yet been investigated, a histological study by Pour et al. involving analysis of serial nerve sections from three pancreatic cancer specimens revealed that cancer cells within the nerves from a tumor, along the superior mesenteric artery to the celiac ganglia, without invasion into surrounding tissues (45).

Another potential explanation is that metastatic rectal cancer cells exhibit neurotropism, and upon hematogenous or lymphatic spread to the nerve-rich retroperitoneum or the liver, they establish a paracrine interaction with nerve fibers that facilitates metastatic growth.

While PNI positivity was associated with poor prognosis and a high risk of recurrence, the new key finding in the present study is that prognosis is better in patients with PNInegative rectal cancer than in those with PNI-positive tumors.
Another new finding in this study is that prognosis became progressively worse going from PNI-negative patients with well-differentiated adenocarcinoma to PNI-negative patients with non-well-differentiated adenocarcinoma to PNI-positive patients, using our tree model. Using the tree model to reveal important independent factors associated with recurrence, PNI was found to be a significant risk factor for recurrence in this study. This result was similar to and confirmed the outcome of analysis using the Cox proportional hazards model.

There may also be a potential role for PNI in therapy stratification in order to select those node-negative patients with rectal cancer who may benefit from existing regimens currently limited to patients with node-positive disease. In Japan, the present 5-year rate for metastasis or recurrence after curative surgery of Dukes' B disease is $13.3 \%$ (29). For oncologists, the decision to administer adjuvant chemotherapy to patients with Dukes' B disease is based on clinical and pathological risk markers (46). High-risk Dukes' B colon cancer has been defined as that having T4 tumor stage, poor histological grade, lymph 


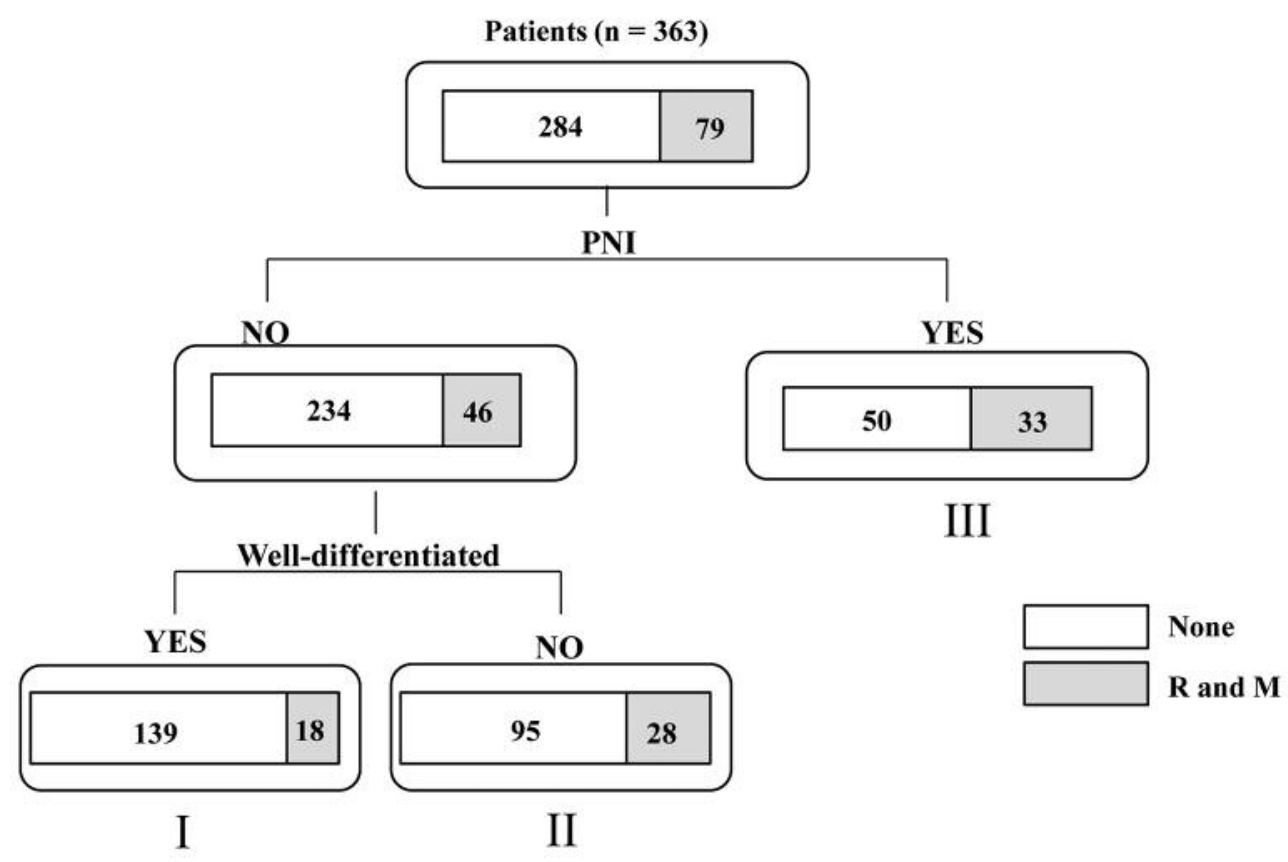

Figure 2. Analysis of the data for patients with rectal cancer using a tree model ( $n=363)$. The response variable is the application of the criterion of whether or not the case was perineural invasion (PNI)-positive. The model resulted in the partitioning of patients into three groups: I: Patients with PNI-negative well-differentiated adenocarcinoma; II: patients with PNI-negative non-well-differentiated adenocarcinoma; and III: patients with PNI-positive cancer. R: Recurrence, M: metastasis, Well: well-differentiated adenocarcinoma.

node invasion or vascular invasion, PNI, bowel obstruction, and fewer than 12 positive lymph nodes $(47,48)$. Recently, there are some reports of prognosis analysis of patients with rectal cancer based on the histopathological findings. Lateral lymph node metastasis has been reported to be related to prognosis in patients with rectal cancer $(30,49)$. Although the relationship between PNI-positive and lateral lymph node metastasis was recognized in this study, its clinical significance is unclear. It is necessary to analyze this relationship in the future.

According to the National Comprehensive Cancer Network guidelines, patients with high-risk Dukes' B colon cancer should be considered for adjuvant chemotherapy. However, a recent retrospective study did not show a survival advantage from adjuvant chemotherapy in such patients (50). According to our findings, for all patients with Dukes' B or C rectal cancer who undergo curative surgery, adjuvant chemotherapy should be offered based on pathological findings, especially PNI positivity, in order to improve prognosis.

The present study was an initial exploratory study. One limitation was its retrospective nature, while another was that oncological data were not available for any control group without adjuvant chemotherapy in patients with Dukes' C disease. Further investigations into the molecular basis of PNI could help develop therapeutic strategies targeted towards this aggressive tumor phenotype.
We conclude that PNI is an underreported phenomenon in rectal cancer. Our data strongly suggest that PNI is a significant prognostic factor in rectal cancer, and support using the PNI status in therapy stratification. The PNI status be incorporated into pathological findings and be deemed indicative of a high risk of recurrence. In particular, patients with PNI-positive Dukes' B disease should be considered candidates for adjuvant chemotherapy in order to avoid recurrence and metastasis.

\section{References}

1 Kotake K, Honjo S, Sugihara K, Kato T, Kodaira S, Takahashi $\mathrm{T}$, Yasutomi M, Muto T and Koyama Y: Changes in colorectal cancer during a 20-year period: an extended report from the multi-institutional registry of large bowel cancer, Japan. Dis Colon Rectum 46: S32-43, 2003.

2 Newland RC, Chapuis PH, Pheils MT and MacPherson JG: The relationship of survival to staging and grading of colorectal carcinoma: a prospective study of 503 cases. Cancer 47: 14241429, 1981.

3 De Angelis R, Sant M, Coleman MP, Francisci S, Baili P, Pierannunzio D, Trama A, Visser O, Brenner H, Ardanaz E, Bielska-Lasota M, Engholm G, Nennecke A, Siesling S, Berrino F and Capocaccia R: Cancer survival in Europe 1999-2007 by country and age: results of EUROCARE-5-a population-based study. Lancet Oncol 15: 23-34, 2014. 

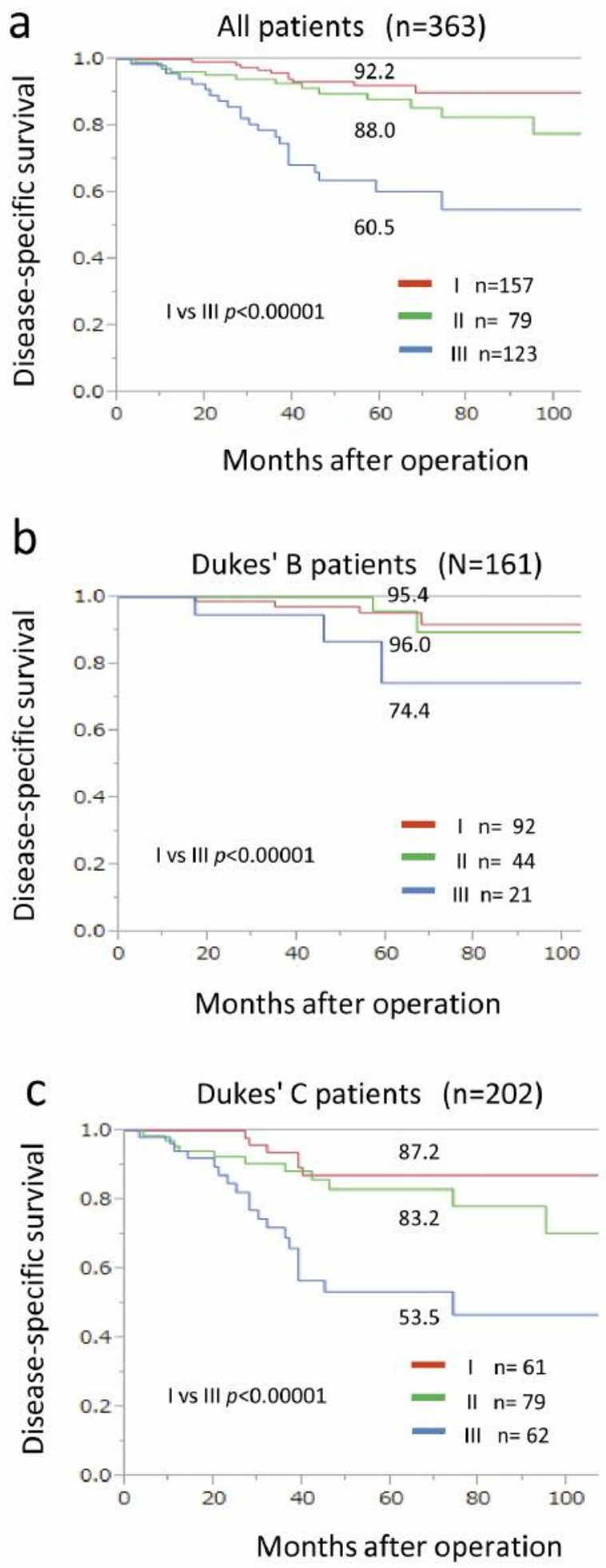

Figure 3. Kaplan-Meier survival curves of disease-specific survival after curative surgery for rectal cancer for all patients (a), those with Dukes' $B$ disease (b), and those with Dukes' $C$ disease (c) according to grouping by tree model. I: Patients with perineural invasion (PNI)-negative welldifferentiated adenocarcinoma; II: patients with PNI-negative non-welldifferentiated adenocarcinoma; and III: patients with PNI-positive cancer.
4 Andreoni B, Chiappa A, Bertani E, Bellomi M, Orecchia R, Zampino M, Fazio N, Venturino M, Orsi F, Sonzogni A, Pace U and Monfardini L: Surgical outcomes for colon and rectal cancer over a decade: results from a consecutive monocentric experience in 902 unselected patients. World J Surg Oncol 5: 73, 2007.

5 Dukes CE: The classification of cancer of the rectum. J Pathol Bacteriol 35: 326-332, 1932.

6 Astler VB and Coller FA: The prognostic significance of direct extension of carcinoma of the colon and rectum. Ann Surg 139: 846-852, 1954.

7 Sobin LH, Gospodarowicz MK and Wittekind C: TNM Classification of Malignant Tumours 7th Edition, John Wiley \& Sons, Wiley-Blackwell, 2009.

8 Jass JR, Love SB and Northover JM: A new prognostic classification of rectal cancer. Lancet 1: 1303-1306, 1987.

9 Morodomi T, Isomoto H, Shirouzu K, Kakegawa K, Irie K and Morimatsu M: An index for estimating the probability of lymph node metastasis in rectal cancers. Lymph node metastasis and the histopathology of actively invasive regions of cancer. Cancer 63: 539-543, 1989.

10 Seefeld PH and Bargen JA: The Spread of Carcinoma of the Rectum: Invasion of Lymphatics, Veins and Nerves. Ann Surg 118: 76-90, 1943.

11 Knudsen JB, Nilsson T, Sprechler M, Johansen A and Christensen $\mathrm{N}$ : Venous and nerve invasion as prognostic factors in postoperative survival of patients with resectable cancer of the rectum. Dis Colon Rectum 26: 613-617, 1983.

12 Krasna MJ, Flancbaum L, Cody RP, Shneibaum S and Ben Ari $\mathrm{G}$ : Vascular and neural invasion in colorectal carcinoma. Incidence and prognostic significance. Cancer 61: 1018-1023, 1988.

13 Shirouzu K, Isomoto $\mathrm{H}$ and Kakegawa T: Prognostic evaluation of perineural invasion in rectal cancer. Am J Surg 165: 233-237, 1993.

14 Moreira LF, Hizuta A, Iwagaki H, Tanaka N and Orita K: Lateral lymph node dissection for rectal carcinoma below the peritoneal reflection. Br J Surg 81: 293-296, 1994.

15 Takahashi Y, Tucker SL, Kitadai Y, Koura AN, Bucana CD, Cleary KR and Ellis LM: Vessel counts and expression of vascular endothelial growth factor as prognostic factors in nodenegative colon cancer. Arch Surg 132: 541-546, 1997.

16 Porter GA, Soskolne CL, Yakimets WW and Newman SC: Surgeon-related factors and outcome in rectal cancer. Ann Surg 227: 157-167, 1998.

17 Enker WE, Thaler HT, Cranor ML and Polyak T: Total mesorectal excision in the operative treatment of carcinoma of the rectum. J Am Coll Surg 181: 335-346, 1995.

18 Paty PB, Enker WE, Cohen AM and Lauwers GY: Treatment of rectal cancer by low anterior resection with coloanal anastomosis. Ann Surg 219: 365-373, 1994.

19 Batsakis JG: Nerves and neurotropic carcinomas. Ann Otol Rhinol Laryngol 94: 426-427, 1985.

20 Veness MJ: Perineural spread in head and neck skin cancer. Australas J Dermatol 41: 117-119, 2000.

21 Rubin MA, Mucci NR, Manley S, Sanda M, Cushenberry E, Strawderman M, Montie JE and Bassily NH: Predictors of Gleason pattern $4 / 5$ prostate cancer on prostatectomy specimens: Can high-grade tumor be predicted preoperatively? J Urol 165: 114-118, 2001. 
22 Beard CJ, Chen MH, Cote K, Loffredo M, Renshaw AA, Hurwitz $\mathrm{M}$ and D'Amico AV: Perineural invasion is associated with increased relapse after external beam radiotherapy for men with low-risk prostate cancer and may be a marker for occult, high-grade cancer. Int J Radiat Oncol Biol Phys 58: 19-24, 2004.

23 Fagan JJ, Collins B, Barnes L, D'Amico F, Myers EN and Johnson JT: Perineural invasion in squamous cell carcinoma of the head and neck. Arch Otolaryngol Head Neck Surg 124: 637640, 1998.

24 Fujita S, Nakanisi Y, Taniguchi H, Yamamoto S, Akasu T, Moriya Y and Shimoda T: Cancer invasion to Auerbach's plexus is an important prognostic factor in patients with pT3-pT4 colorectal cancer. Dis Colon Rectum 50: 1860-1866, 2007.

25 Di Fabio F, Nascimbeni R, Villanacci V, Baronchelli C, Bianchi D, Fabbretti G, Casella C and Salerni B: Prognostic variables for cancer-related survival in node-negative colorectal carcinomas. Dig Surg 21: 128-133, 2004.

26 Burdy G, Panis Y, Alves A, Nemeth J, Lavergne-Slove A and Valleur P: Identifying patients with T3-T4 node-negative colon cancer at high risk of recurrence. Dis Colon Rectum 44: 1682$1688,2001$.

27 Liebig C, Ayala G, Wilks J, Verstovsek G, Liu H, Agarwal N, Berger DH and Albo D: Perineural invasion is an independent predictor of outcome in colorectal cancer. J Clin Oncol 27: 51315137, 2009.

28 Shirouzu K and Ogata Y: Histopathologic tumor spread in very low rectal cancer treated with abdominoperineal resection. Dis Colon Rectum 52: 1887-1894, 2009.

29 Japanese Society for Cancer of the Colon Rectum Guidelines 2014 for the Treatment of Colorectal Cancer, Seventh Edition. Tokyo, Japan, Kanehara Shuppan, 2014.

30 Kinugasa T, Akagi Y and Shirouzu K: Benefit of lateral lymph node dissection for rectal cancer: long-term analysis of 944 cases undergoing surgery at a single center (1975-2004). Anticancer Res 34: 4633-4639, 2014.

31 Neumann E: Secondare cancroid infiltration des nerves mentails bei einem. Arch Pathol Anat 24: 201, 1862.

32 Ozaki H, Hiraoka T, Mizumoto R, Matsuno S, Matsumoto Y, Nakayama T, Tsunoda T, Suzuki T, Monden M, Saitoh Y, Yamauchi $\mathrm{H}$ and Ogata $\mathrm{Y}$ : The prognostic significance of lymph node metastasis and intrapancreatic perineural invasion in pancreatic cancer after curative resection. Surg Today 29: 16-22, 1999.

33 Law WL and Chu KW: Anterior resection for rectal cancer with mesorectal excision: a prospective evaluation of 622 patients. Ann Surg 240: 260-268, 2004.

34 Duraker N, Sisman S and Can G: The significance of perineural invasion as a prognostic factor in patients with gastric carcinoma. Surg Today 33: 95-100, 2003.

35 Harnden P, Shelley MD, Clements H, Coles B, Tyndale-Biscoe RS, Naylor B and Mason MD: The prognostic significance of perineural invasion in prostatic cancer biopsies: a systematic review. Cancer 109: 13-24, 2007.

36 Ozcan F: Correlation of perineural invasion on radical prostatectomy specimens with other pathologic prognostic factors and PSA failure. Eur Urol 40: 308-312, 2001.

37 Epstein JI, Amin M, Boccon-Gibod L, Egevad L, Humphrey PA, Mikuz G, Newling D, Nilsson S, Sakr W, Srigley JR, Wheeler TM and Montironi R: Prognostic factors and reporting of prostate carcinoma in radical prostatectomy and pelvic lymphadenectomy specimens. Scand J Urol Nephrol Suppl: 34-63, 2005.
38 Mendenhall WM, Amdur RJ, Hinerman RW, Werning JW, Malyapa RS, Villaret DB and Mendenhall NP: Skin cancer of the head and neck with perineural invasion. Am J Clin Oncol 30: 93-96, 2007.

39 Horn A, Dahl O and Morild I: Venous and neural invasion as predictors of recurrence in rectal adenocarcinoma. Diseases of the colon and rectum 34: 798-804, 1991.

40 Matsushima T, Mori M, Kido A, Adachi Y and Sugimachi K: Preoperative estimation of neural invasion in rectal carcinoma. Oncol Rep 5: 73-76, 1998.

41 Peng J, Lu JJ, Zhu J, Xu Y, Lu H, Lian P, Cai G and Cai S: Prediction of treatment outcome by CD44v6 after total mesorectal excision in locally advanced rectal cancer. Cancer $\mathbf{J}$ 14: 54-61, 2008.

42 Gunderson LL, Sargent DJ, Tepper JE, Wolmark N, O’Connell MJ, Begovic M, Allmer C, Colangelo L, Smalley SR, Haller DG, Martenson JA, Mayer RJ, Rich TA, Ajani JA, MacDonald JS, Willett CG and Goldberg RM: Impact of $\mathrm{T}$ and $\mathrm{N}$ stage and treatment on survival and relapse in adjuvant rectal cancer: a pooled analysis. J Clin Oncol 22: 1785-1796, 2004.

43 Lombardi R, Cuicchi D, Pinto C, Di Fabio F, Iacopino B, Neri S, Tardio ML, Ceccarelli C, Lecce F, Ugolini G, Pini S, Di Tullio P, Taffurelli M, Minni F, Martoni A and Cola B: Clinically-staged T3N0 rectal cancer: Is preoperative chemoradiotherapy the optimal treatment? Ann Surg Oncol 17: 838-845, 2010.

44 McCuskey RS: Anatomy of efferent hepatic nerves. Anat Rec A Discov Mol Cell Evol Biol 280: 821-826, 2004.

45 Pour PM, Bell RH and Batra SK: Neural invasion in the staging of pancreatic cancer. Pancreas 26: 322-325, 2003.

46 Tournigand $\mathrm{C}$ and de Gramont A: Chemotherapy: Is adjuvant chemotherapy an option for stage II colon cancer? Nat Rev Clin Oncol 8: 574-576, 2011.

47 Compton C, Fenoglio-Preiser CM, Pettigrew N and Fielding LP: American Joint Committee on Cancer Prognostic Factors Consensus Conference: Colorectal Working Group. Cancer 88: 1739-1757, 2000.

48 Benson AB, 3rd, Schrag D, Somerfield MR, Cohen AM, Figueredo AT, Flynn PJ, Krzyzanowska MK, Maroun J, McAllister P, Van Cutsem E, Brouwers M, Charette M and Haller DG: American Society of Clinical Oncology recommendations on adjuvant chemotherapy for stage II colon cancer. J Clin Oncol 22: 3408-3419, 2004.

49 Kinugasa T, Akagi Y, Ochi T, Ishibashi Y, Tanaka N, Oka Y, Mizobe T, Yuge K, Fujino S, Kibe S and Shirouzu K: Lateral lymph-node dissection for rectal cancer: meta-analysis of all 944 cases undergoing surgery during 1975-2004. Anticancer Res 33: 2921-2927, 2013.

50 O'Connor ES, Greenblatt DY, LoConte NK, Gangnon RE, Liou JI, Heise CP and Smith MA: Adjuvant chemotherapy for stage II colon cancer with poor prognostic features. J Clin Oncol 29: 3381-3388, 2011. 